\title{
Resumen / Los olvidados de Luis Buñuel
}

La película Los olvidados de Luis Buñuel muestra, aparentemente, los efectos que los factores ambientales tienen sobre los sujetos socialmente marginales. Estos sujetos son excluídos de la ciudad moderna, la cual es un símbolo de progreso social y de las ventajas que se le atribuyen a la ciudadanía. Estos sujetos, por lo tanto, ocupan un territorio invisible e inhóspito, un no lugar.

¿Como releer una película basada en una denuncia realista de la miseria en el contexto histórico mexicano asociado con el empuje traumático y acelerado hacia una economía moderna que caracterizó la administración de Miguel Alemán (1946-1952) desde la posición subjetiva de la propia disidencia social y sexual? Para contestar esta pregunta se utilizará el concepto de punctum de Roland Barthes para interpretar la representación del socialmente periférico otro. En Los olvidados esta representación del perférico otro, contra el cual la sociedad burguesa se define, desarma los paradigmas hegemónicos de sexo, género y clase que estructuran la subjetividad burguesa y heteronormativa, precisamente por ser rastros heterogéneos y discontinuidades de los procesos simbólicos.

En otro nivel se utilizará la noción de Real de Lacan para proponer una crítica de lo que se define como realismo dentro del orden hegemónico de nuestra cultura.

\section{Palabras clave}

Imaginario - punctum - real resistencia - relacional - sexual - simbólico social - subversivo - transgresión.

\section{Summary / Los olvidados by Luis Buñuel}

The film Los olvidados [The Young and the Damned] by Luis Buñuel apparently shows the effects of the environmental factors on those subjects excluded from society. These subjects are excluded from the modern city, which becomes a symbol of social progress, and the advantages of citizenship. Therefore, these subjects take up an invisible and inhospitable territory, a no-place.

How can a film based on a realistic report about misery within a Mexican historic context associated with a traumatic and accelerated drive towards the modern economy characterized by Miguel Alemán's administration (1946-1952) can be re-read from the subjective position of the own social and sexual dissidence? Roland Barthes' concept of punctum will be used to answer this question in order to understand the representation of the socially peripheral other. In Los olvidados, this representation of the peripheral other -against whom the bourgeois society defines itself- dismantles the hegemonic paradigms of sex, gender and class which structure the bourgeois and heteronormative subjectivity, precisely because they are heterogeneous traces and discontinuities of the symbolic processes.

In a different level, Lacan's notion of Real will be used to propose a criticism of that defined as realism within the hegemonic order in our culture.

\section{Key words}

Imaginary-punctum - real resistance - relational - sexual - subversive - symbolic meaning - transgression.

*Julián Daniel Gutiérrez Albilla. Magister de literatura hispanoamericana de la Universidad de Cambridge. Realiza su tesis de doctorado en dicha Universidad acerca del cine de Buñuel en el período transcurrido en México. infocedyc@palermo.edu 


\section{Resumen / Los olvidados de Luis Buñuel}

O filme Los olvidados de Luis Buñuel apresenta, aparentemente, os efeitos que os fatores ambientais têm sobre os sujeitos socialmente marginais. Estes sujeitos são excluídos da cidade moderna, símbolo de progresso social e das vantagens atribuídas a cidadania. Estes sujeitos, em tanto, ocupam um espaço invisível e inóspito, um não lugar.

¿Como reler um filme baseado numa denuncia realista da miséria no contexto histórico mexicano associado com uma força traumática e acelerada em direção a uma economia moderna que caracterizou a administração de Miguel Alemán (1946-1952) desde a posição subjetiva da própria dissidência social e sexual? Para responder esta pergunta se utilizará o conceito de punctum de Roland Barthes para interpretar a representação do socialmente periférico outro. Em Los olvidados esta representação do periférico outro, em contra a sociedade burguesa se define, desarma os paradigmas hegemônicos de sexo, gênero e classe que estructuram a subjetividade burguesa e heteronormativa, precisamente por ser rastros heterogêneos e descontinuidades dos processos simbólicos.

Em outro nível se utilizará a noção de Real de Lacan para propor uma crítica do que se define como realismo dentro do ordem hegemônico da nossa cultura.

\section{Palavras chave}

Imaginário - punctum - real resistência - relacional - sexual - simbólico social - subversivo - trangressão. 


\section{El encuentro con lo Real. La alteridad social y la fragmentación de cuerpos en Los olvidados de Luis Buñuel}

A estas almas desposeídas, el espacio les parece ser una fuerza devoradora. El espacio los persigue, los rodea y los digiere en un consumo gigantesco de bacterias. Éste termina reemplazándolos. Después, el cuerpo se separa del pensamiento, el individuo rompe el límite de su piel y ocupa el otro lado de sus sentidos. Trata de mirarse desde cualquier punto en el espacio. Se siente convertido en espacio oscuro donde las cosas no pueden ser puestas. Se parece, no se parece a algo; sino que simplemente se parece. Inventa espacios donde él es la posesión convulsa. ${ }^{1}$

El análisis de Roger Caillois sobre el comportamiento de los insectos que se camuflan dentro del ambiente, asociándolos a formas esquizofrénicas de la pérdida de la identidad, podría ilustrar, metafóricamente, el que parece ser el interés principal de una película realista social como Los olvidados (1950). La película muestra, aparentemente, los efectos que los factores ambientales tienen sobre el desarrollo de los sujetos socialmente marginales. Estos sujetos pobres son excluídos de la ciudad moderna, la cual es un símbolo de progreso social, y de las ventajas que se atribuyen a la ciudadanía. Estos sujetos, por lo tanto, ocupan un territorio invisible e inhóspito. ${ }^{2}$ ¿Pero cómo podemos pensar en este territorio invisible e inhóspito desde una posición subjetiva que esté localizada fuera de un espacio imaginable o habitable? ¿Cómo podemos, entonces, releer una película basada en una denuncia realista de la miseria en el contexto histórico mexicano asociado con el empuje traumático y acelerado hacia una economía moderna industrial que caracterizó la administración de Miguel Alemán (1946-1952) desde la posición subjetiva de la propia disidencia social y sexual? Para contestar a esta pregunta, en un nivel, partiré del concepto de punctum de Roland Barthes para interpretar la representación del 'otro socialmente periférico' y del cuerpo fragmentado como detalles puntuales que se escapan de la intencionalidad de Buñuel, y argumentaré que en Los olvidados la representación del "otro socialmente periférico", contra el cual la sociedad burguesa se define, desarma los paradigmas hegemónicos de sexo, género y clase que estructuran la subjetividad burguesa y heteronormativa, precisamente por ser rastros heterogéneos y discontinuidades de los procesos simbólicos. En otro nivel, utilizaré la noción de lo Real de Lacan para proponer una crítica del realismo, o de lo que se define como realismo dentro del orden hegemónico de nuestra cultura.

Esta aproximación alternativa explora la manera en que Los olvidados, mediante una trasgre-sión del significado simbólico, se puede interpretar como obra subversiva desde el punto de vista sexual y social. Intentaré explicar esta concepción alternativa de la sexualidad y la socialidad, la cual está ya posiblemente implícita en la propia teoría lacaniana, llevando así al psicoanálisis a un punto de autocrítica. ${ }^{3}$

\section{El punctum de Roland Barthes}

En Camera Lucida, Roland Barthes identifica la fotografía como un espectáculo esencialmente atormentado. Barthes distingue dos órdenes de contacto con el espectáculo de la fotografía. El primero, menos intenso, es el nivel codificado del studium, el cual pertenece al orden del gusto o desagrado y representa una especie de educación en términos del conocimiento y la cortesía. Para Barthes, el studium, como un modo racional y lineal de leer la fotografía, es un instrumento analítico para reconciliar el mito peligroso de la fotografía con prácticas socialmente aceptadas. ${ }^{4}$ El studium produce su efecto característico por su misma carencia de patetismo, su neutralidad afectiva, así no apela a las emociones del espectador.

El interés seguro y cortés del studium contrasta con el placer intenso o el dolor del punctum descifrado, el cual rompe o puntúa el studium (Barthes, Camera Lucida, p. 26). El punctum, como un fragmento electrificante que se apodera de la imaginación y la viola, apela a las emociones del espectador, despertando en él un deseo por un desposeimiento de sí mismo. El punctum, el cual es a menudo un detalle, y está sujeto a una cierta latencia, "emerge en la escena, sale disparado de ella como una flecha, y me perfora. Existe una palabra latina para designar esta herida, esta perforación, esta señal causada por un instrumento puntiagudo. Esta palabra me conviene aun mejor porque también se refiere a la noción de penetración" (Barthes, Camera Lucida, pp. 26-27). El punctum, entonces, no está asociado con la voluntad, ya que escapa a la intencionalidad del fotógrafo. Dicha desvalorización de la voluntad corresponde a la valorización de la memoria involuntaria. Para Barthes, el punctum participa en una economía de exceso, ya que es siempre suplementario, marginal y descentrado. Influenciado por Bataille, Barthes asocia el punctum con un gasto inútil sin intercambio y con el placer de jouissance. Desde esta perspectiva, la fotografía se convierte en un texto erótico, el cual viola la felicidad, mediante un proceso que se escapa de la lógica del ego-cogito y en el transcurso del cual el sujeto contacta con otras lógicas que son indiferentes a las categorías morales y estéticas. El sujeto también lucha con el significado y con la muerte. Esto es para Barthes el interés último y la catástrofe final de la fuerza quebrantadora del punctum.

Aunque todo sistema de representación artística, como el cine, la fotografía o el texto literario, está dotado de una modalidad específica del detalle, el efecto del punctum en la fotografía puede ser directamente aplicable a otros medios artísticos, incluyendo el cine. Jo Labanyi sugiere, con acierto, que las fotografías como los fotogramas de las películas, juegan un papel importante como imágenes de un pasado fragmentario, discontinuo, espectral. ${ }^{5}$

En este artículo, argumentaré que algunos detalles puntuales en Los olvidados pueden o no pueden 
parecer estar disociados de la estructura semiótica de la película. Entiendo estos detalles puntuales, los cuales no garantizan la intencionalidad de Buñuel, como significantes específicos que incorporan afirmaciones y transgresiones sexualmente y socialmente disidentes. De la misma manera que el punctum, estas afirmaciones o transgresiones están asociadas con el placer de jouissance.

Este placer social y sexualmente disidente en la pérdida y la desorientación subjetiva perfora la organización social y simbólica del orden del significado de la ideología dominante cuyo objetivo es el control social, visible o invisible. Mi lectura de los detalles puntuales en la película articula una fantasía sobre las estrategias transgresivas que resulta indispensable para la teoría del género y la sexualidad (Dean, Beyond Sexuality, 262). ¿Cómo puede esta fantasía permitir imaginarnos o prever una interconexión entre la disidencia sexual y otras categorías de exclusión social que no pudieran estar directamente conectadas con la sexualidad, como el "otro socialmente periférico"?

La otredad social y la estética del realismo social ¿Cómo podemos pensar la alteridad social para proponer una compleja identificación positiva con la diferencia en Los olvidados? Según la noción de "interpelación" de Althusser, la ideología dominante impone nuevas relaciones desiguales de subordinación dentro del complejo de los aparatos ideológicos estatales mediante la construcción de una ilusión de identidad individual y libertad de elección. ${ }^{6}$

La noción de Althusser nos ayuda a pensar el proceso de exclusión social y discriminación que ocurre dentro de dichas prácticas institucionales. La crítica de Althusser al poder institucionalizado permite, sin embargo, la posibilidad de contestación dentro de aquellos mecanismos de interpelación ideológica y de opresión social. Dominic Keown, por ejemplo, ha elaborado una lectura marxista/althusseriana de la obra de Buñuel según la cual sus protagonistas se rebelan contra su propia conformidad dentro de dictados ideológicos. Según Keown, la mayor parte de los críticos del cine de Buñuel sólo han considerado la posición ideológica de Buñuel en términos de su crítica feroz a la burguesía. Utilizando la filosofía social marxista, el acercamiento de Keown aclara cómo en las películas de Buñuel, "Existe una preocupación por la condición ontológica del individuo en un sistema capitalista". ? Desde esta perspectiva, en Los olvidados, la representación del "otro socialmente periférico" requiere una reconsideración del problema de la exclusión e invisibilidad social principalmente en sociedades modernas burguesas y salvajemente capitalistas. Esta formulación política en la película nos permite por tanto situarnos en una posición crítica ideológica y políticamente oposicionista a la ideología hegemónica.

¿Puede la representación del "otro socialmente periférico" en Los olvidados estar ligada a una comodificación del mundo marginal, reinscribiendo así aquellas mismas preconcepciones ideológicas que la película intenta derribar? ¿El "otro socialmente periférico" se presenta a sí mismo como una entidad asociada a la categoría de lo Real de Jacques Lacan: aquella entidad sin forma, aquel rastro o exceso (surplus) que se resiste a la simbolización, en otras palabras, aquello que identificamos con una otredad traumática y, quizá, indeseada que no puede ser ni representada ni incorporada por el sujeto? Lo Real se identifica con lo inexpresable, con aquello sobre lo que no se puede hablar, puesto que no pertenece al sistema lingüístico. ${ }^{8}$ El orden Real se asocia con las dimensiones de la sexualidad y la muerte. Si un significante adecuado no puede representar el inteligible Real, la manifestación de lo Real sólo se puede lograr mediante el artificio de lo abyecto. Si lo Real no se puede representar, puede repetirse y tiene que entenderse de una manera presimbólica o postsimbólica. Dicho retorno de lo Real como trauma implica un giro de la "realidad como un efecto de la representación a lo Real lacaniano como un ente traumático". 9 Lo Real es relacional y oposicional, en un sentido subversivo, ya que se resiste a la asimilación dentro de cualquier universo imaginario o simbólico y a la incorporación dentro de la economía del sujeto, por tanto el sujeto queda incapacitado y desposeído de su propio ser.

Desde una perspectiva ortodoxamente marxista, la asociación del "otro socialmente periférico" con la pre-ontológica noción de lo Real de Lacan podría ser vista como una desubjetivización del sujeto marginal. Dicha relegación del sujeto socialmente marginal a un espacio de inexistencia, al espacio de lo innombrable e invisible, contradice la opinión marxista sobre el subproletariado como una clase articulada y estructurada situada en la posición central de la lucha revolucionaria por el cambio social que estas sociedades injustas tienen que sufrir. Aparte del prólogo de la película, la narrativa de la película no ofrece ni explicaciones sociales, económicas, políticas ni soluciones a la situación del subproletariado. Por tanto, la película podría considerarse como un espectáculo exótico y erótico de la pobreza del Tercer Mundo y de los cuerpos del Tercer Mundo que Buñuel ofrece al público del Primer Mundo. ${ }^{10}$ Sin embargo, esta teoría marxista ortodoxa no toma en consideración la cuestión de la heterogeneidad del deseo, incluyendo el deseo perverso, en las formaciones ideológicas. ${ }^{11}$ La cuestión del "otro socialmente periférico" podría ser reinterpretada dentro de un marco epistemológico que transgreda la terminología rígida dentro de la crítica cultural marxista promoviendo la política de la perversión y de la alteridad y empujándola hacia el punto del nihilismo. Este acercamiento hacia la alteridad es emancipatorio y deshace la sutura del sujeto a las leyes del orden hegemónico social y simbólico.

Con respecto a la cuestión del realismo social, existe en Los olvidados, hasta cierto punto, una preocupación política asociada con la protesta social contra los valores ideológicos de la revolución institucional 
en México durante los años `50. La película también se opone a la retórica dogmática nacionalista y las convenciones visuales del cine clásico mexicano, el cual evolucionó a partir de la tradición visual revolucionaria. ${ }^{12}$ Funcionando, tal vez, como un documental social, la película parece construir una representación verdadera ${ }^{13}$ de las vidas de los niños callejeros como una estrategia política para denunciar la injusticia social, como la pobreza, en la sociedad urbana coetánea mexicana. Funcionando así como una revisión de la mitología revolucionaria propagada por las películas melodramáticas durante la época dorada del cine mexicano, como las películas de Emilio Fernández, Los olvidados ha sido considerada como un precedente oblicuo de un nuevo cine en América Latina que se pudiera definir como de auteur, abiertamente militante, de orientación izquierdista y formalmente experimental, ejemplificado por la generación posclásica de directores mexicanos, cubanos, argentinos y brasileiros. Este nuevo cine, al cual se suele hacer referencia como el Nuevo Cine Latinoamericano, surgió a finales de los años `50 y a principios de los años `60 para luchar contra el neocolonialismo que, aunque todavía estaba ligado a fuentes europeas, cada vez se identificaba más con los Estados Unidos. ${ }^{14}$

Influenciado por Vittorio de Sica, Buñuel utiliza la estética del neorealismo italiano para conseguir esta ruptura estética y epistemológica con las convenciones visuales y morales del cine clásico mexicano y del cine de Hollywood. Por ejemplo, aparte de algunas secuencias y elementos surrealistas dentro de la película, Los olvidados parece privilegiar un descarnado interés realista en los problemas sociales del supuesto Tercer Mundo, a través del uso sustancial de actores no profesionales, utilización mayoritaria de lugares reales en lugar de estudios y una cinematografía no demasiado estilizada. Desde esta perspectiva, en Los olvidados, Buñuel transforma esta estética italiana dentro de un contexto específicamente mexicano o latinoamericano con la finalidad de concentrarse en la acción política, adquiriendo consecuentemente una nueva posición estética, moral y política que despierte la conciencia social. Buñuel no recurre, sin embargo, al folklore oficial o a los símbolos nacionales propagados por el cine clásico. Según Buñuel, estos símbolos nacionales eran un producto de la manipulación política y una aberración burguesa. ${ }^{15}$ Por consiguiente, un verdadero mensaje político puede comunicarse dentro de una estética del realismo social en vez de a través de la belleza prefabricada asociada con las prácticas artísticas oficiales. Buñuel, por tanto, indica una nueva dirección para el cine mexicano y latinoamericano cuya estética del realismo social puede hablar directamente del racionalismo de los modelos políticos para el cambio social deseado.

Además, aparte del uso de la banda sonora, Los olvidados también desafía la viabilidad de usar la estética romántica o el naturalismo sentimental del cine clásico mexicano ${ }^{16}$ para llevar a cabo la tarea revolucionaria de destruir asunciones ideológicamente regresivas y criticar la distribución injusta de capital en México durante los años `50. El cine clásico mexicano se había vuelto políticamente enajenante debido a su asociación con el melodrama y a su imitación del paradigma de Hollywood. Negándose a reconocer el proceso de modernización de México, el cine clásico mexicano se había convertido, por tanto, en inadecuado y contraproducente como una práctica cinematográfica que procurase promover la liberación sociopolítica en el umbral de la modernidad. Confrontando este proceso de modernización social, Los olvidados, entonces, declara una cierta independencia del realismo convencional establecido en el cine clásico mexicano. Como explica J. Hoberman: "LoS olvidados no se adscribe al naturalismo sentimental a través del cual la industria cinematográfica mexicana (incluso la neorrealista - los dramas de barrios bajos de Alejandro Galindo, Nosotros los pobres de Ismael Rodríguez), representaba tradicionalmente la pobreza indígena. "17

Sin embargo, este acercamiento estético, político y epistemológico no reconoce los elementos de fantasía en el discurso buñueliano y no reconoce la imposibilidad de una forma objetivamente estricta del realismo sin estar éste mediado por alguna intrusión de ninguna forma de subjetividad. Ana López afirma que cualquier pretensión de proporcionar una verdadera representación de la realidad está condicionada por lo que la cultura ve como auténtico en una época específica. López sugiere que dicha afirmación señalaría "una ingenua creencia en la capacidad de la cámara de registrar las verdades para capturar una realidad nacional o la esencia sin ningún tipo de mediación como si una simple inversión de la cultura dominante fuera suficiente para negar dicha cultura e instituir una verdadera" ${ }^{18}$ El énfasis de López en la cuestión de la mediación, para desafiar la noción de autenticidad en el cine, nos hace pensar en los efectos de las convenciones, géneros, formas y otras clases de artificio en lo que podría parecernos como un realismo mimético.

Barthes también formula la pregunta sobre qué es lo real, en particular en su ensayo 'The Reality Effect', en el cual desmitifica la noción de una verdad transparente en el seno de la entidad del realismo mimético. ${ }^{19}$ Para Barthes, el realismo es un señuelo o "una ilusión de referencia", a través del cual el referente se convierte en el significante verdadero para formar una "vraisemblance" no declarada ('The Reality Effect', p. 10). Cuando uno piensa que está en posesión de lo real en su materialidad concreta, uno está bajo un efecto de la realidad, en donde lo que se nos ofrece es una categoría y no un ente. ${ }^{20}$ Dollimore ha argumentado que "para algunos, éste es un momento de decepción en el cual lo verdadero, lo real o lo auténtico está rendido o contaminado por lo ficticio y artificial". ${ }^{21}$

La película está inspirada por noticias periodísticas sobre la miseria urbana, por la propia experiencia antropológica del director en algunos barrios bajos 
de Ciudad de México, y también hace referencias a personajes auténticos. Evans sugiere, sin embargo, que "Los olvidados se mueve más allá de la prosa del documental hacia la poesía del Gótico mexicano, transformando la escoria en metáfora, lo ordinario en lo fantástico, lo conocido en lo desconocido y molesto". ${ }^{22}$ García Riera sugiere que Buñuel introduce estos "elementos de irracionalidad para no seguir al pie de la letra un argumento, una realidad fotográfica". ${ }^{23}$ Además, basándonos en un entendimiento psicoanalítico de lo Real extrapolado de las lecturas del psicoanálisis lacaniano, la noción de lo Real que este artículo propone capturar es un Real que va más allá de la representación de cuestiones reales y convenciones de verosimilitud en el cine. Desde esta perspectiva, la película recupera lo heterogéneo dentro de la idea homogénea de la razón ${ }^{24}$ para pensar la representación como vinculada con un compromiso parcial y fantasmagórico con lo que el psicoanálisis lacaniano define como lo Real. Edmond Cros sugiere que "la obra filmográfica de Luis Buñuel está dominada por un realismo radical que no se detiene en las fronteras de lo visible en la medida en que lo real representado se encuentra siempre convocando lo invisible". ${ }^{25}$ Este énfasis en lo Real es un giro dentro de la teoría lacaniana que se aleja de lo simbólico. Esta asociación de la representación con la imposibilidad de capturar lo Real parece abrir el campo del significado, ampliarlo fuera de la cultura y, como veremos, subvertir no sólo el contenido sino la práctica total del significado.

\section{Lo cosmético y lo abyecto. El cuerpo de la ciudad y el cuerpo femenino}

Los olvidados empieza con unos planos fijos que muestran las chabolas de una ciudad moderna y un título que proclama que la película está completamente basada en hechos reales y que todos los personajes son auténticos. Aunque la película está principalmente rodada en lugares auténticos, también utiliza escenarios en estudios de rodaje que simulan las chabolas de los barrios bajos. La miseria de estos barrios bajos ultrapoblados y sucios está visualmente lograda por la dirección artística de Edward Fitzgerald y la fotografía de Gabriel Figueroa, quien colaboró con Buñuel en varias de sus películas del período mexicano. El estilo cinematográfico de Figueroa estaba asociado con el formalismo físico de las películas de Emilio Fernández. Las películas de este último director, a menudo, muestran los cielos hermosos y paisajes exóticos de México. En dichas películas, la cinematografía de Figueroa se caracteriza por el empleo de la "perspectiva oblicua", la cual se diferencia de la "perspectiva monocular". ${ }^{26}$ Esta última está asociada con la tradición pictórica occidental. Mientras la "perspectiva monocular" acentúa la tridimensionalidad del espacio dentro de la escena, como si la imagen fuera una ventana a través de la cual se ve el mundo exterior, la "perspectiva oblicua" acentúa la carencia de profundidad de la escena. La diferente concepción del espacio que Figueroa articula con respecto a la tradición pictórica europea y norteamericana se puede interpretar como una estra- tegia de representación visual que formaba parte de la retórica nacionalista mexicana, la cual era esencial en el proyecto de colaboración artística entre Fernández y Figueroa.

Es importante aclarar cómo ciertos críticos ortodoxos del cine latinoamericano han rechazado la posibilidad de poder representar estética y/o artificialmente la miseria social en Los olvidados, o en cualquier otra película que se pueda definir como realista social. Dichos críticos han favorecido el neorealismo como un lenguaje más adecuado para crear filmes que enfaticen no la forma sino su contenido significativo de denuncia social o política. Algunas críticas coetáneas de Los olvidados, incluso, condenaron la película por el mero hecho de contener algunos elementos heterogéneos que no podían contenerse dentro de una estética realista pura. Por ejemplo, Bosley Crowther, crítico de cine en el New York Times, encontró la película "morbosa" y "chocante". Crowther afirmó que aunque este "semi-documental mexicano" esté realizado con un realismo meticuloso y una incuestionable fidelidad a hechos reales, su calificación como entretenimiento dramático, o incluso como reportaje social, es débil. Buñuel ha orquestado otra clase de transgresión' ${ }^{27}$

Contra la entidad mimética que está en el seno de la defensa del realismo social a expensas de o en detrimento del artificio irónico asociado con la representación visual, podríamos, entonces, releer la imagen de los barrios bajos en Los olvidados como una celebración de una estética que definiremos como "estética basura". Dicha celebración de la "estética basura" también puede funcionar para derribar el orden burgués tanto social como simbólicamente. ${ }^{28}$

En Los olvidados, Buñuel intenta capturar los interiores sórdidos que los seres humanos comparten con los animales, y que están abarrotados de detritos, para reflejar la depravación urbana. Al final de la película, el cadáver de Pedro es depositado en una montaña de basura que está localizada en un barrio bajo de la ciudad. El cuerpo muerto del niño termina realizando su condición como residuo. Por tanto, el cuerpo de Pedro es colocado, literalmente, en el espacio que la sociedad burguesa mexicana lo había obligado a habitar simbólicamente.

Si celebramos la "estética basura" en la película, como un lugar mixto y sincrético la basura mezcla lo rico con lo pobre, el centro con la periferia, convirtiéndose en un lugar de memorias enterradas y rastros. Este lugar de sorprendentes yuxtaposiciones violentas explora el espacio donde los símbolos no son estables, donde los conceptos de "heces" (dinero o regalo), "bebé", y "pene" no se distinguen uno del otro y son fácilmente permutables (Foster, The Return of the Real, p. 164). La "estética basura" en Los olvidados captura el sentido de marginalidad, de estar condenado a sobrevivir dentro de una condición de escasez, de ser el basurero que destila e irónicamente reapropia las contradicciones de la sociedad. 
Sin embargo, ésta también tiene una dimensión espiritual al transformar objetos sin valor en algo valioso. De ahí que dicha estética se convierta en una estrategia artística que desafía la distribución burguesa del espacio y las relaciones subjetivas burguesas, celebrando la escoria, los residuos y el rechazo de todas las clases. La "estética basura" se opone, entonces, a la organización formal, la sublimación cultural y la racionalización ideológica o la redención.

La imagen de apertura y el título de Los olvidados son seguidos por varias tomas de modernos centros urbanos metropolitanos, como Nueva York, París y Londres, los cuales Buñuel compara con Ciudad de México, porque todas estas ciudades modernas son los motores de la industrialización y están habitadas por una enorme clase social hambrienta. La cámara muestra monumentos típicos y edificios que caracterizan estas metrópolis modernas hasta el punto de convertirse en significantes vacíos de contenido que flotan en la superficie de la sociedad de consumo y del espectáculo, como la Torre Eiffel en París o el Big Ben en Londres. Estas imágenes estereotípicas de los modernos centros urbanos, las cuales se equiparan a mediocres postales turísticas, están acompañadas por la voz superpuesta de un narrador que explica directamente a la audiencia el problema de la pobreza en estas ciudades industrializadas. Por consiguiente, entendemos que la pobreza no desaparece como consecuencia del cambio de una economía agrícola a una industrial. El narrador, por tanto, parece impugnar una concepción teleológica de la historia, la cual es producto de un modelo de pensamiento positivista, al denunciar en estas tomas de apertura la distribución desigual de la riqueza en México así como en los países europeos y norteamericanos.

Sin embargo, la solución inmediata que el narrador propone contradice su supuesto objetivo ideológicamente subversivo. El narrador sugiere una solución para combatir la pobreza que está basada, paradójicamente, en la misma concepción teleológica de la historia dentro del marco de la modernidad que produce simultáneamente la alteridad social a la vez que la intenta relegar a espacios invisibles. Teniendo en cuenta dichas contradicciones ideológicas internas en la escena de apertura, podríamos leer la película como un comentario irónico contra la imagen de cohesión social, progreso y reforma que era propagada por los discursos oficiales mexicanos a expensas de la negación y silenciación neurótica de las causas estructurales que provocaban el crimen juvenil y la marginalidad social, los cuales molestan y avergüenzan a los discursos oficiales.

El mensaje directo de la voz superpuesta del narrador a la audiencia nos obliga a tomar cierta responsabilidad social sobre lo que estamos a punto de presenciar. El empleo de Buñuel de técnicas documentales produce una representación aparentemente realista de la situación social. Como explicábamos antes, este efecto de verismo sociológico y autenticidad es una estrategia fílmica que se utiliza para manipular la relación entre el espectador y el tema de la película. Este realismo "no-mediado", el cual intenta desatender el proceso mediático de la cámara y el proceso fílmico, da la sensación al espectador de que el cine no es la representación de la realidad, sino la propia realidad.

Es interesante notar cómo la cámara realiza una inclinación hacia arriba de modo que el espectador pueda prestar atención a estas atracciones turísticas que convierten a estas ciudades modernas en objetos de consumo. La cámara también ofrece vistas panorámicas de estas ciudades modernas. Una toma aérea del Zócalo se disuelve en una escena que muestra un grupo de niños callejeros que juegan a torear en uno de los suburbios miserables y caóticos que aparecen fantasmagóricamente en Ciudad de México. Julia Tuñón sugiere que "la metrópolis moderna, limpia y ordenada sólo será real, si acaso, para un grupo social y se acomoda en tensión constante en el avasallante proceso de crecimiento urbano" (Tuñón: 79). Esta primera escena en uno de esos arrabales nos permite percibir cómo lo abyecto social, lo cual relacionaremos con la noción lacaniana de lo Real, puede filtrarse a través de la fachada cosmética de la modernidad burguesa. Como apunta Tuñón, "la modernidad es tan sólo una apariencia que contradice los discursos oficiales y deshace las ilusiones de algunos" (Tuñón: 87). Esta borrosa confusión de la línea entre la fachada cosmética de la modernidad burguesa y la de lo socialmente abyecto se vuelve amenazante y genera una situación de horror y ansiedad. Podemos ampliar este análisis para sugerir que en Los olvidados lo socialmente abyecto se puede asociar con una brecha o amenazada herida en la piel de la modernidad. Tuñón sigue explicando que, "la primera ruptura de la ciudad es con el suburbio, que, en algunos momentos, parece una herida de la ciudad, y, en otros, un apéndice estorboso e inútil". (Tuñón: 85)

En términos psicoanalíticos, este espacio socialmente abyecto añade una dimensión fantasmagórica a aquella yuxtaposición o punto donde dos significados coinciden directamente y se hacen indistinguibles. Buñuel parece llevar a un primer plano aquel "objeto vacío", el cual es simultáneamente el "grano íntimo" y el "cuerpo extraño" localizado en la frontera entre términos opuestos, recuperando lo socialmente abyecto que se oculta detrás de la máscara superficial de la modernidad. El "objeto vacío", que Lacan define como l'extimité, apunta hacia aquello que no es ni exterior ni interior, pero que rompe la piel continua para revelar el "centro vacío", el espacio de lo Real. ${ }^{29}$ Si asociamos lo socialmente abyecto con la noción lacaniana de lo real, Los olvidados revela y destapa la serie de estrategias defensivas de protección o aplazamiento de la ciudad moderna que tienen que ser llevadas a cabo en la frontera entre el interior y el exterior para cubrir el "objeto vacío" o aplazar el encuentro con la Cosa.

Varias acciones que se desarrollan a lo largo de la película, como la agresión violenta hacia la figura 
patriarcal del ciego o el asesinato sádico de Julián que comete Jaibo con ayuda del ingenuo Pedro, ocurren delante de una especie de estructura metálica que parece el esqueleto de una construcción que nunca se pudo llevar a cabo, como si dicha estructura representase gráficamente una cierta alusión simbólica a cómo los mitos de la ilustración y de la modernidad son un proyecto incompleto. Por tanto, la puesta en escena representa la coexistencia incompatible entre el impulso de construcción y el de destrucción, coexistencia de impulsos que se encuentra en el seno de la modernidad. Como afirma Tuñón, "La ciudad moderna es un espacio que al habitarse olvida, que al urbanizarse deshumaniza y que al edificarse destruye" (Tuñón: 93). En el contexto específico de Latinoamérica, el proyecto de modernización ha sido frenado por la dependencia colonial de España, país que ha sido históricamente uno de los menos industrializados de la Europa occidental. Además, la yuxtaposición de diferentes temporalidades y tradiciones culturales en Latinoamérica, que Néstor García Canclini ha definido como "heterogeneidad multitemporal" ha impedido una evolución "natural" de una producción agrícola a una industrializada. ${ }^{30}$ Por ejemplo, en la cinta de Buñuel, vemos frecuentemente cómo aparecen gallinas porque éstas representan la irracionalidad y el rastro de un mundo rural en un mundo urbano precario. Como Tuñón describe:

"En el barrio, en la casa de Meche duermen todos juntos en el mismo cuarto, pero sí existe una habitación separada para los animales: el establo, en donde hay una burra, una cabra y un cabrito, además de gallinas y gallos, de abundante presencia en este filme. También en la casa de Pedro hay gallinas. Alcoriza hace notar que las imágenes de corrales y establos existían porque su presencia era constante en los arrabales de la ciudad."

En su crítica sociocultural feminista de Los olvidados, Jean Franco argumenta que Buñuel desafía el paternalismo autoritario de los años del Porfiriato desde 1876 hasta 1911. Dicho paternalismo autoritario todavía atormenta al paternalismo benévolo del estado reformista propagado por el gobierno de la Revolución institucionalizada de Miguel Alemán, en el cual Los olvidados se contextualiza. Según Franco, la película subvierte la imagen oficial de México realizando una transición fácil hacia la modernidad. ${ }^{31}$ Si el concepto del cuerpo humano se ha aplicado a lo largo de la historia moderna al proyecto de construcción de las ciudades, Franco atribuye la coexistencia incompatible del impulso de construcción con el de destrucción al problema de la modernización desigual en México en donde lo arcaico se convierte en una área no redimida e irredimible que la ciudad moderna racional necesita expulsar de su cuerpo. Según la asociación metafórica que realiza Franco entre la ciudad moderna y el cuerpo humano, la ciudad tiene que expulsar los cadáveres de los dos protagonistas, Pedro y Jaibo, como parte del proceso simbólico de exclusión, purificación y organización que apuntala la transición a la modernización en México durante los años cuarenta y cincuenta.

En la secuencia surrealista que muestra el sueño de Pedro, Buñuel explícitamente desafía la superficie de realismo de la película. En dicha secuencia, Pedro ve el cadáver de Julián, el cual está cubierto en sangre y riéndose debajo de la cama, y ve como su madre se acerca a él en cámara lenta, una técnica fílmica que Buñuel no utiliza normalmente en otras películas. Marta habla con Pedro sin mover sus labios, y la voz de Pedro también es incorpórea y además no está sincronizada. La madre de Pedro le ofrece un trozo desgarrado de carne cruda que Jaibo le arrebata. La presencia amenazadora de Jaibo en el sueño de Pedro puede señalar cómo la expresión de un vínculo entre dos hombres se puede representar a través de su rivalidad por una mujer. ${ }^{32}$ La carne cruda, la cual se asemeja a un feto abortado, funciona como una metáfora o un desplazamiento metonímico del cuerpo de la madre de Pedro.

Evans, influenciado por la asociación que realiza Barbara Creed entre la noción de lo abyecto con lo femenino en las películas pertenecientes al género de horror, argumenta que la carne cruda puede interpretarse como la vagina rasgada de Marta, la cual es el objeto de terror y de deseo del inconsciente masculino y funciona en contraposición a la negación de la carencia percibida del pene según la noción freudiana de fetichismo (The films of Luis Buñuel, pp. 85-86). Desde la perspectiva de Evans, la aparición monstruosa de Marta en el sueño de Pedro simboliza la figura de la mujer como castradora en lugar de castrada, como la define Freud. Además, según Parveen Adams:

“Una aparición es tanto sublime como terrible; una aparición es silenciosa, quedando fuera del significado. Pienso que Lacan dibuja una imagen de una aparición hablando sobre el toique viene a nuestros labios en una tentativa de encontrar el significante del resto, aquello que no puede ser significado. El toi es una referencia al otro de jouissance, al otro primario, al Otro pre-simbólico - un Otro muy diferente al Otro del lenguaje." ${ }^{33}$

Esta asociación entre lo abyecto y lo femenino es reforzada por la teorización de Laura Mulvey sobre la relación dialéctica entre el cuerpo cosmético y el abyecto en su análisis sobre las diferentes autorepresentaciones que realiza la fotógrafa contemporánea Cindy Sherman. Según Mulvey, el interés temático de Sherman pasa de centrarse en el artificio externo, el cual quedaba reflejado en las fotografías de su primera época, a centrarse en la "monstruosidad" interna y el horror de su cuerpo que explora en sus series fotográficas de los años '80, como "Anti-fashion", "Fairy Tales", "Disgust" o "Bulimia". El análisis de Mulvey sobre las auto-representaciones de Sherman se precipita hacia el significado sin tomar apenas en consideración la operación de los signifi- 
cantes, como el encuadre, la iluminación, la distancia, el ángulo de cámara, la textura, los marcos internos o la profundidad del campo visual. Sin embargo, el desarrollo que Sherman lleva a cabo desde lo cosmético a lo abyecto permite a Mulvey argüir que "Esta imagen parodia grotescamente el tipo de imagen femenina que se utiliza para su consumición erótica e invierte los códigos convencionales sobre la atracción y la elegancia femenina". ${ }^{34}$

Después de esta presentación de los puntos de vista de Evans y Mulvey sobre la relación dialéctica entre la feminidad cosmética y lo abyecto, me gustaría retomar la idea de Franco sobre el cuerpo de la ciudad con la finalidad de establecer una analogía entre la 'otredad monstruosa' (según el término de Evans) que se localiza detrás de la máscara cosmética de la feminidad en el cuerpo de la madre de Pedro y aquello que se reprime o se excluye en la construcción del cuerpo de la ciudad moderna. Esta es una "ciudad rota, maltrecha, escenario preciso para sus personajes que siempre buscan, escenario paralelo a los cuerpos torturados y desmembrados que fascinan al director" (Tuñón: 87). En Los olvidados, aquello que se reprime o se excluye del cuerpo de la ciudad es ejemplificado por lo abyecto social. Además, Mulvey explica que, aunque la noción freudiana de fetichismo tiene que distinguirse de la noción marxista, tanto Marx como Freud conectan el fetichismo con la función de ocultamiento (Fetishism and Curiosity, pp. 47-48). En la noción marxista, el fetiche cosificado oculta una red de relaciones sociales. En la noción freudiana, por otro lado, el fetichismo sexual oculta la falta sobre la cual la red simbólica se articula. Por tanto, tanto Marx como Freud ofrecen una crítica del sujeto moderno, revelando como la construcción de las estructuras sociales y simbólicas se lleva a cabo en formas de fetiches. Asímismo, si la ideología del fetiche es también la ideología del falocentrismo burgués, lo Real subvierte los mecanismos simbólicos de negación que se construyen en relación a lo abyecto dentro de dicha ideología. La relación dialéctica entre lo cosmético y lo abyecto en el cuerpo femenino y en la ciudad moderna en Los olvidados revela la propia fragilidad de estos cuerpos. Si lo cosmético niega la materialidad de la imagen, lo abyecto reintroduce y reafirma lo táctil, lo físico, lo visceral. La noción de tactilidad ha sido reprimida en la construcción de un modelo racional de pensamiento, el cual está en el seno del proyecto de la modernidad. Lo Real, por consiguiente, subvierte los mecanismos de negación de la herida percibida que el fetichista construye en relación al cuerpo femenino y que la modernidad construye en relación a lo abyecto social.

Consecuentemente, en Los olvidados, lo real se convierte en un rastro traumático. Lo Real provoca una ansiedad y revela la vulnerabilidad psíquica en la subjetividad patriarcal y burguesa, la cual se construye culturalmente a través de una dialéctica compleja de poder. Si el cuerpo suave, fragmentado, líquido está unido a aquello que se constituye como lo otro, este tipo de cuerpo en la película es una amenaza al ego, ya que se concibe a partir de provocar la posibilidad de su disolución y de alcanzar un estado de no-diferenciación. Lo Real, en esta secuencia de Los olvidados, no ha sido expulsado. Desde esta perspectiva, la película apunta hacia la manera en que la subjetividad moderna contiene el sujeto Real dentro de su mandato simbólico. Como hemos argumentado, el proyecto de la ilustración requiere el repudio de los detritos de sí mismo. Este proceso de exclusión requiere un monstruo, el cual representa todo aquello que la cultura moderna tiene que reprimir. No obstante, éste monstruo de la ilustración revela cómo este proyecto está marcado por su propio fracaso de una determinación completa. Como apunta Mladen Dolar:

"La ideología consiste en un intento social de integrar lo ominoso, hacerlo soportable, asignarle un lugar, y la crítica de la ideología está atrapada en el mismo marco si trata de reducirla a otro tipo de contenido o hacer dicho contenido consciente y explícito." 35

En resumen, la película de Buñuel desafía la ideología hegemónica porque ésta necesita afirmar su poder social mediante la expulsión de lo visceral, lo táctil, lo abyecto de su cuerpo. Así pues, Lo Real en LoS olvidados se asocia con un extásis demoledor o una ruptura traumática que destruye al sujeto moderno con estas imágenes que vemos en la película de cuerpos humanos y urbanos fragmentados que a su vez funcionan como tropos del "monstruo horrífico" de lo reprimido. Como apunta Teresa Vilarós, "esta cosa que cae" es por otra parte lo que siempre acecha en forma de "monstruo" que quiere salir a la luz, desvelarse". 36

Para concluir, me gustaría volver a la cuestión del problema de la pobreza urbana en ciudad de México. Mi relectura de Los olvidados no descarta la posibilidad de que la película se lea como una denuncia realista de dicho problema durante el gobierno de Miguel Alemán a finales de los años `40 y principios de los `50. Por otro lado, me ha interesado explorar cómo la cinta de Buñuel insiste en el dolor o placer (jouissance) que procede de la imposibilidad de desprendernos de aquel efecto sublime que no se aparta de nosotros hagamos lo que hagamos ${ }^{37}$ para rechazarlo y desecharlo. La película, entonces, representa lo que he identificado como el imposible Real, estableciendo lo puntual en una temporalidad y localidad fuera, o en los límites, de un determinismo histórico o ideológico. Este imposible Real quiebra y desplaza la noción teleológica de una historia progresiva y entera elaborada en los discursos de la política oficial de Miguel Alemán. Este imposible Real es una profunda fisura que recorre los cimientos de los precarios edificios de los arrabales de Ciudad de México, un doloroso quiste o tumor que se incuba en el cuerpo enfermo y fragmentado de la ciudad moderna burguesa, y que produce en la frágil e inestable construcción del sujeto patriarcal y heterosexista un peculiar desgarro, una grieta irreparable. 


\section{Notas}

1 Roger Caillois, "Mimicry and Legendary Psychasthenia", October, 31 (1984), 17-32 (p. 30).

2 Julia Tuñón (2003) "Cuerpo humano y cuerpo urbano en Los olvidados", in Buñuel: The Transcultural Imaginary, ed. by Gastón Lillo. Ottawa: University of Ottawa, pp. 69-89 (p. 72).

3 Tim Dean (2000) Beyond Sexuality. Chicago: University of Chicago Press.

4 Roland Barthes (1982) Camera Lucida: Reflections on Photography, trans. by Richard Howard. London: Jonathan Cape, pp. 26-27.

5 Jo Labanyi (1998) Rescuing the Living Dead from the Dustbin of History: Popular Memory and Postwar Trauma in Contemporary Spanish Film and Fiction. Bristol: University of Bristol, Department of Hispanic, Portuguese and Latin American Studies, p. 5.

6 Louis Althusser (1971) "Ideology and Ideological State Apparatuses", in Lenin and Philosophy and Other Essays. New York: Monthly Review Press, pp. 127-86.

7 Dominic Keown, "The Critique of Reification: A Subversive Current within the Cinema of Contemporary Spain" (1996) in European Identity in Cinema, ed. by Wendy Everett. Exeter: Intellect Books, pp. 61-73 (p. 61).

8 Jacques Lacan (1978) The Four Fundamental Concepts of Psychoanalysis, trans. by Alan Sheridan. New York: W.W. Norton.

9 Hal Foster (1996) The Return of the Real: The AvantGarde at the End of the Century . Cambridge, MA: MIT Press, p. 146.

10 La película fue muy controvertida cuando se estrenó en México. Por otro lado, los amigos surrealistas de Buñuel, como Aragón y Breton, celebraron la película cuando asistieron a una proyección privada del filme en París en 1951. Agustín Sánchez Vidal, Luis Buñuel (1984). Obra cinematográfica . Madrid: Ediciones JC. En el archivo de Buñuel en la Residencia de Estudiantes en Madrid, hay una invitación original al estreno diseñado por Jean Cocteau con un poema de Jacques Prévert. Este material gráfico demuestra la recepción exitosa de la película mexicana dentro del círculo vanguardista francés. Además, Los olvidados ganó el premio de la Mise-en-scène en la 4 a edición del festival cinematográfico de Cannes en 1951

11 "Preface", in Formations of Fantasy, ed. by Victor Burgin, James Donald, and Coral Kaplan (1986). London: Methuen, pp. 1-3.

12 Ernesto Acevedo-Muñoz (2003).Buñuel and Mexico: The Crisis of National Cinema (Berkeley, CA: University of California Press.

13 Buñuel intentaba ser fiel a la realidad en vez de crear un espacio para la articulación de la Mexicanidad. Dicha articulación era la preocupación principal de la cultura visual revolucionaria. Sin embargo, en una entrevista, Buñuel confesó que él nunca rompió sus lazos con el surrealismo, incluso aunque él no fuera más parte del movimiento en un sentido oficial u ortodoxo. La declaración de Buñuel parece ir en contra del realismo que se ha acentuado en Los olvidados. André Bazin y Jacques DoniolValcroze, "Conversation with Buñuel", Sight and Sound, 24.4 (Spring 1955), pp. 181-85.

14 John King (1990). Magical Reels: A History of Cinema in Latin America. London: Verso, p. 66.

15 Acevedo-Muñoz (1997). "Los olvidados: Luis Buñuel and the Crisis of Nationalism in Mexican Cinema", (unpublished paper, Latin American Studies Association, p. 4.

${ }^{16}$ Emilio García Riera (1998). Breve historia del cine mexicano: primer siglo, 1897-1997. Jalisco: Ediciones Mapa, p. 175.

17 J. Hoberman, (1983). "Los olvidados", American Film, 8 14-15, p. 14.

18 Ana López (1990) "At the Limits of Documentary: Hypertextual Transformation and the New Latin American Cinema", in The Social Documentary in Latin America, ed. by Julianne Burton. Pittsburgh: University of Pittsburgh Press, pp. 403-32 (p. 408).

19 Roland Barthes (1982) "The Reality Effect", in French Literary Theory Today: A Reader, ed. by Tzvetan Todorov. Cambridge: Cambridge University Press, pp. 11-17

20 Naomi Schor (1987) Reading in Detail: Aesthetics and the Feminine. New York and London: Methuen, p. 86

21 Jonathan Dollimore (1991) Sexual Dissidence: Augustine to Wilde, Freud to Foucault. Oxford: Clarendon Press, p. 312.

22 Peter Evans (1995). The Films of Luis Buñuel: Subjectivity and Desire. Oxford: Clarendon Press. $p$. 78.

23 Emilio García Riera (1993). Historia documental del cine mexicano. Jalisco: Universidad de Guadalajara, p. 192.

24 James Lastra (1999) "Why Is This Absurd Picture Here? Ethnology/Equivocation/Buñuel", October, 89, pp. 51-68.

25 Edmond Cros (2003) "De Piero della Francesca a Los olvidados. El texto cultural de la figura crística", in Buñuel: The Transcultural Imaginary, ed. by Gastón Lillo. Ottawa: University of Ottawa, pp. 21-32 (p. 29). ${ }^{26}$ Charles Ramírez Berg (1992) "Figueroa`s Skies and Oblique Perspective: Notes on the Development of the Classical Mexican Style", Spectator, 13.2 24-41 (p. 37).

27 Citado por J. Hoberman, Los olvidados, p. 15.

28 Robert Stam and Ella Shohat (1999) "Narrativizing Visual Culture: Towards a Polycentric Aesthetics", in Visual Culture: A Reader, ed. by Jessica Evans and Stuart Hall. London: Sage in association with the Open University. pp. 27-49.

29 Briony Fer (1997). On Abstract Art (New Haven: Yale University Press, p. 148.

30 Néstor García Canclini (1995) "Modernity after Postmodernity", in Beyond the Fantastic: Contemporary Art Criticism from Latin America, ed. by Gerardo Mosquera. London: Institute of International Visual Arts, pp. 20-51.

31 Jean Franco (1989) Plotting Women: Gender and Representation in Mexico. London: Verso, p. 153. 
32 Eve Kosofsky Sedgwick, Between Men 1985). English Literature and Male Homosocial Desire. New York: Columbia University Press.

33 Parveen Adams (1991) "The Art of Analysis: Mary Kelly"s Interim and the Discourse of the Analyst", October, 58, 81-96, p. 93.

34 Laura Mulvey (1996). Fetishism and Curiosity. London: British Film Institute, p. 70.

35 Mladen Dolar (1991) "I Shall Be With You On Your Wedding Night: Lacan and the Uncanny", October, 58, Fall, 5-23, p. 19.

36 Teresa Vilarós (1998). El mono del desencanto. Una crítica cultural de la transición española (1973-1993). Madrid: Siglo Veintiuno, p. 11.

37 Slavoj iek (1997). The Plague of Fantasies. London: Verso, p. 165.

* Mis más profundos agradecimientos a Sylvia Valdés, Paul Julian Smith y Angeles Carreres por sus observaciones interesantes y su ayuda valiosa con este artículo. 